\title{
NEW RECORD OF DICRANELLA RIPARIA (H. LINDB.) MÅRT. ET NYH. (DICRANACEAE, MUSCI) IN RUSSIA
}

\author{
НОВАЯ НАХОДКА DICRANELLA RIPARIA (H. LINDB.) MÅT. ET NYH. \\ (DICRANACEAE, MUSCI) В РОССИИ
}

\author{
IRINA V. CZERNYADJEVA ${ }^{1}$ \\ ИРИНА ВИТАЛЬЕВНА ЧЕРНЯДЬЕВА ${ }^{1}$
}

Abstract

Dicranella riparia, known previously in Russia only from the Isthmus Karelicus (Leningrad Province), is reported from the Yamal Peninsula. Description, illustrations, differentiotion characters and habitat data are provided.

Резюме

\begin{abstract}
Dicranella riparia, ранее известная в России только с Карельского перешейка (Ленинградская область), найдена на п-ове Ямал. Приводятся описание вида, иллюстрации и данные о его местообитании.
\end{abstract}

Dicranella riparia was originally described (as Oncophorus riparius) from Valkjarvi (Isthmus Karelicus, Leningrad Province, Russia) by $\mathrm{H}$. Lindberg (1900). Since when the plant has been found in Norway, Sweden and Greenland (Molinaar, 1974; Nyholm, 1986). Generic position of $D$. riparia was problematic for a long time. This species was placed to Oncophorus (Lindberg, 1900), Cynodontium (Roth, 1904), Kiaeria (Corley, 1974). However Nyholm (1986) definitely showed its position within Dicranella.

During identification of my arctic moss collections from the Yamal Peninsula, a specimen of $D i$ cranella riparia was found. It is described below.

Dicranella riparia (H. Lindb. ) Mårt. et Nyh., Bot. Not., 1954. (Fig. 1)

Oncophorus riparius H. Lindb., Medd. Soc. F. Fl. Fenn., 1900.

Plants yellow-green, stems 4-10 mm high. Leaves erect-spreading, flexuose, lower leaves $1.5-2.0 \mathrm{~mm}$ long, from lanceolate base gradually narrowed into sharp, channelled, point, upper ones 1.7-3.0 $\mathrm{mm}$ long, from \pm sheathing base narrowed into fine, serrulate point; margins plane to partly incurved in upper part, serrulate at apex to entire; costa percurrent to excurrent, about $1 / 5$ width of leaf base; cells in upper part at leaf rectangular to quadrate, in basal part of leaf cells shortly rectangular, enlarged, wider. Perichaetial leaves 2.7-3.5 $\mathrm{mm}$ long, from sheathing base suddenly narrowed into long setaceous point. Autoicous. Seta 10-20 $\mathrm{mm}$ long, when young yellowish, dark below, when old reddish; capsule inclined, curved, asymmetric, strumose, striate when dry; urn 0.8-1.3 mm long; peristome red, devided about halfway, longitudinally striate at the base; operculum $0.8-1.3 \mathrm{~mm}$, obliquely rostrate; annulus of 1-2 rows large cells. Spores $16-20 \mu \mathrm{m}$, smooth or nealy so.

In the Yamal Peninsula D. riparia was collected among Calliergon stramineum (Brid.) Kindb., Pohlia nutans (Hedw.) Lindb., Scapania hyperborea Jørg. on spot of bare sand in nival sedge-moss plant association.

Specimen examined: West Siberian Arctic, Yamal Peninsula, Lower Erkutayaha River, $68^{\circ} 08^{\prime}$ $\mathrm{N}-6^{\circ} 20^{\prime} \mathrm{E}$, Yarono trading station, 29.VII.1994, I.V. Czernyadjeva (LE).

Dicranella riparia is a distinct species. It is related to D. cerviculata (Hedw.) Schimp., D. heteromalla (Hedw.) Schimp. and D. subulata (Hedw.) Schimp., differing from them in combination of characters shown on Table 1.

Acknowledgements. I am very grateful to Dr. A. D. Potemkin for critical reading of the manuscript and for the help with English translation. The work was supported by the Russian Foundation for Fundamental Reaserches (grants 98-04-49828, 98-04-49827).

1 - Irina V. Czernyadjeva. Department of Lichenology and Bryology Komarov Botanical Institute. Prof. Popov Street 2, St. Petersburg, 197376 Russia 


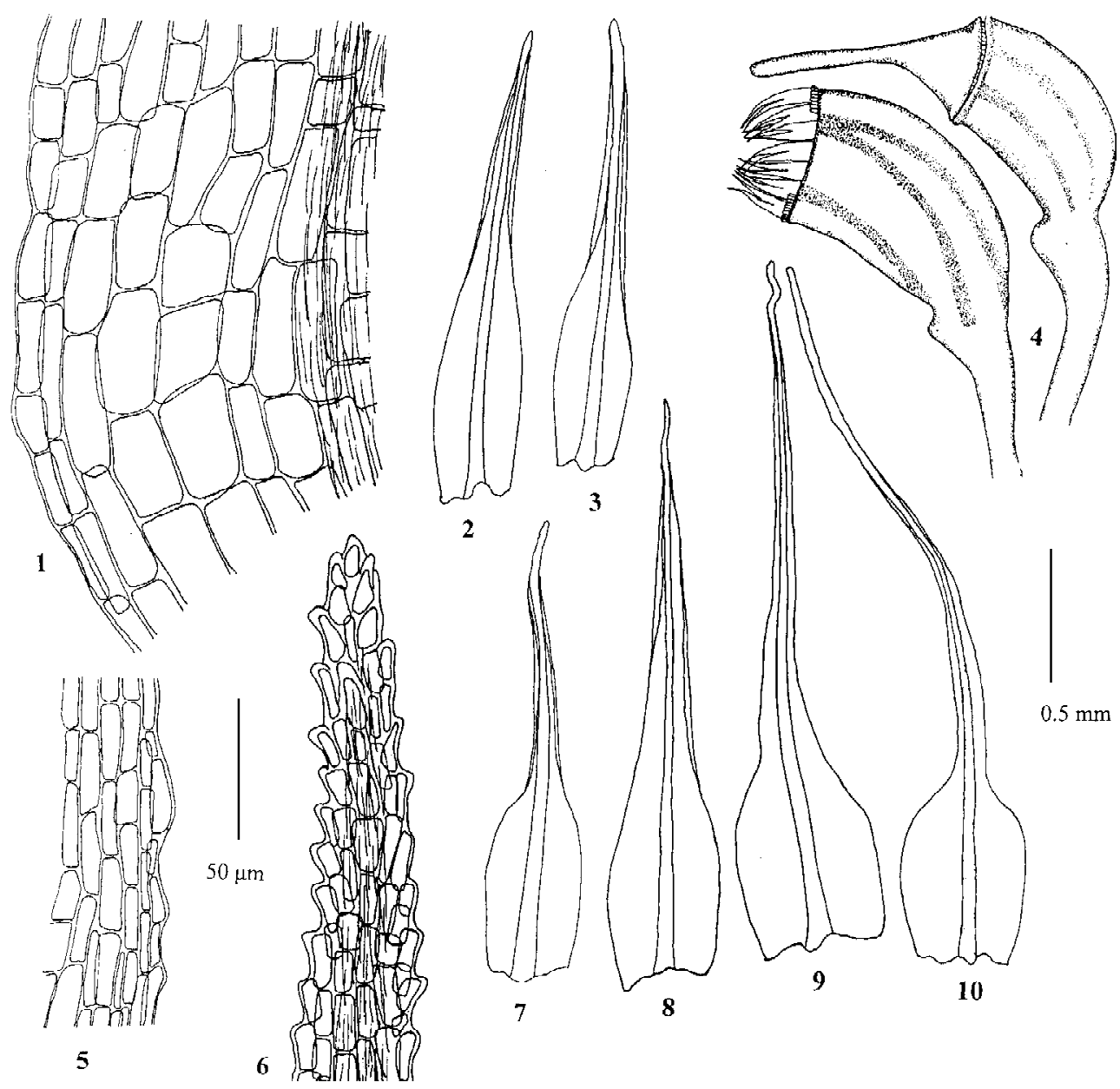

Fig. 1. Dicranella riparia (H. Lindb.) Mårt. et Nyh. (from Yamal Peninsula Czernyadjeva 29.VII.1994): 1 - alar cells; 2-3 - lower leaves; 4 - capsules; 5 - median laminal cells; 6 - upper laminal cells; 7-8 - upper leaves; 9-10 - perichaetial leaves. Scale bars: $50 \mu \mathrm{m}$ for 1, 5-6; $0.5 \mathrm{~mm}$ for 2-4, 7-10.

Tabl. 1. Diagnostic characters of Dicranella riparia and related species.

\begin{tabular}{|c|c|c|c|c|}
\hline $\begin{array}{l}\text { Character } \backslash \text { species } \\
\text { sexuality } \\
\text { capsule } \\
\text { annulus }\end{array}$ & $\begin{array}{c}\text { D. riparia } \\
\text { autoicous } \\
\text { with struma } \\
1-2 \text { rows } \\
\text { of large cells }\end{array}$ & $\begin{array}{l}\text { D. cerviculata } \\
\text { dioicous } \\
\text { with struma } \\
\text { poorly } \\
\text { differentiated }\end{array}$ & $\begin{array}{c}\text { D. heteromalla } \\
\text { dioicous } \\
\text { without struma } \\
\text { poorly } \\
\text { differentiated }\end{array}$ & $\begin{array}{c}\text { D. subulata } \\
\text { dioicous } \\
\text { without struma } \\
\text { 1-2 rows } \\
\text { of large cells }\end{array}$ \\
\hline $\begin{array}{l}\text { leaves } \\
\text { in upper part } \\
\text { width of costa } \\
\text { in leaf base }\end{array}$ & serrulate & almost entire & serrulate & almost entire \\
\hline
\end{tabular}

\section{LITERATURE CITED}

CORLEY, M. F. V. 1979. Notes on some rare Dicranaceae. - J. Bryol. 10(4): 383-386.

LINDBERG, H. 1900. Trenne för den finska floran nya mossor. - Meddelanden af Societas pro Fauna et Flora Fennica 24: 28-29.

DE MOLINAAR, J.G. 1974. Dicranella riparia new to
Greenland. - Bryologist 77: 236-238.

NYHOLM, E. 1986. Illustrated Flora of Nordic Mosses. Fasc. 1. - Copenhagen \& Lund, Nordic Bryol. Soc.: $1-72$.

ROTH, G. 1904. Europäischen Laubmoose. Bd. 1. Leipzig: 1-576. 